\title{
Innovative Practice in Class Teaching of Higher Vocational and Technical Education in the Era of Internet +
}

\author{
Ning Zhai \\ College of Business Administration, Jilin Engineering Normal University, 130052
}

\begin{abstract}
Facing changes of students and study in the era of the Internet, this essay, based on the theory of "Learning Pyramid", discusses two problems---what kind of class teaching is effective and what should be used to push the innovation and reform of class teaching, elaborating on from the course system design of top talents training programs to the basic enforcement of innovation practice of SPOC and micro-flip classes, putting forward the Insurance System Construction of the innovation of class teaching.
\end{abstract}

Keywords: Internet +; Teaching innovation; Personnel training programmes; Flip the classroom; SPOC

\section{互联网+时代的高职课堂教学创新实践}

\section{翟宁}

(吉林工程技术师范学院工商管理学院, 吉林 长春 130052 )

摘要: 面对互联网时代学生和学习的变化, 从“学习金字塔”的理论依据着手, 探讨什么样的课堂教学是有效性和用 什么来推动课堂教学创新与改革两个问题, 详细论述从顶层人才培养方案的课程体系设计, 到基础实施 SPOC 和微课翻转课 堂的创新实践, 并提出课堂教学创新的保障机制建设。

关键词: 互联网+; 课堂教学创新; 人才培养方案; 翻转课堂; SPOC

\section{1 互联网+时代教育模式与中国市场分析}

我国的在线教育近几年发展迅速, 但与西方发达国家相比, 仍处于起步阶段。按照现有的典型在线教 育商业模式来看，在线教育有 B2C、C2C、020、M0OC 等多种模式 [1]。另外，基于在线教育的个性化学习 平台也层出不穷, 像扫题答疑、提供题库或考试平台等 (如图 1)。2012 年起, 美国顶尖大学也陆续设立 网络学习平台, MOOC (Massive Open Online Course, 大规模开放网络课程) 以教育 “平台” 方式在美国 爆发。目前, 在美国超过 2800 所大学中, 超过 70\%的学术领袖认为在线教育与面授教育效果一样或更好。

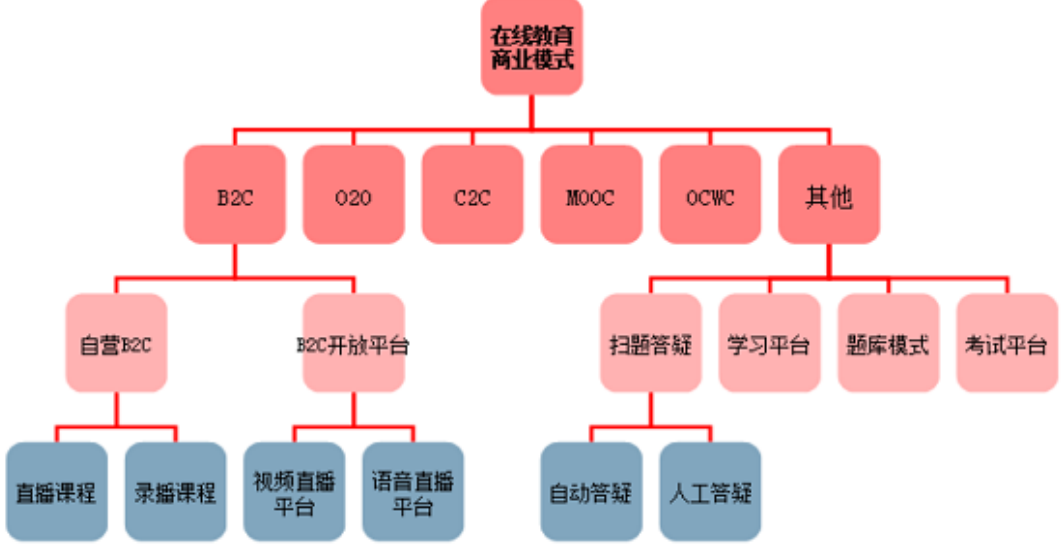

图 1 在线教学育商业模式 
根据中国互联网络信息中心 (CNNIC) 近期发布的《第 38 次中国互联网络发展状况统计报告》，截至 2016 年 6 月, 我国在线教育用户规模达 1.18 亿，较 2015 年底增长 $7.0 \%$ 。手机在线教育用户规模为 6987 万，与 2015 年底相比增长 31. 8\% [2]。应用互联网教育具有非常大的前景。

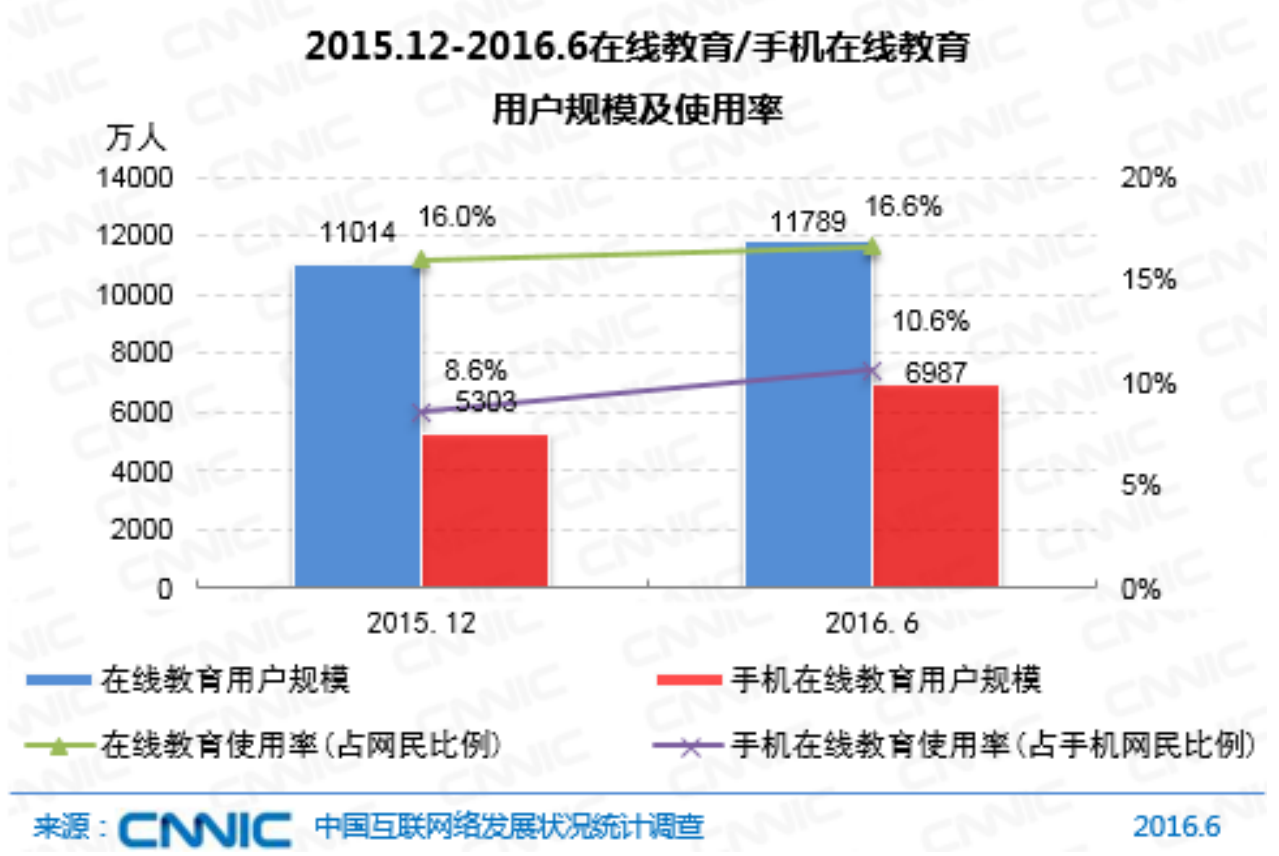

图 2 中国在线教育市场规模

\section{2 高等教育面临的问题与挑战}

在线开放课程 MOOC 是一种新型在线教学模式。据不完全统计 , 目前的各大平台的 MOOC 课程总数 多达上万门, 有些知名高校的 MOOC 课程在线学习人数达到十几万, MOOCs 典型代表互联网+课堂的新 型教学形态正在给高等教育带来一场颠覆性的变革。

\section{1 传统课堂教学面临的现实问题}

\section{1 .1 教学效率低、师生体验差。}

以教师讲授为主的传统课堂, 往往事陪功半, 让师生都倍感急。现在的很多高校教师尤其是高职院校 的教师, 由于教学任务重、学生学习自主性较差, 常常感到工作压力大、成就感差, 易产生倦急感 [3]。 对学生而言, 在大部分传统的讲授课堂上, 老师滔滔不绝满堂灌, 学生被动听讲, 课堂互动较少, 学生的 好奇心、兴趣、潜力没有得到发, 丧失学习兴趣。数据显示, 只有 $37.7 \%$ 同学在课外每周会将 14 小时 以上时间用在学习上 (除上课外), 经常去上自习同学不足 $40 \%$, 接近 $50 \%$ 同学认为课程不能激励学习 或说不清, $79.4 \%$ 同学很少在课内课外与教师讨论。

\section{1.2 对学生创新能力培养不足。}

传统课堂教学主要是依靠教师讲授为主, 学生大多停留在 “理解+记忆” 的浅层次学习, 缺乏问题 分析和思辨能力 [4]。《The Engineer of $2020 》$ 中提出, 当代大学人才培养应该具备包括分析能力、实践 经验、创造力、团队合作与沟通能力、商务与管理能力、领导力、伦理道德与专业精神、适应变化的能力、 终身学习能力等在内的创新能力。如何构建起 “知识探究、能力培养、人格养成、塑造” 四维一体创新 
型人才培养体系是高职教育与经济社会发展同步的现实需求。

\section{2 高职课堂教学有效性的思考}

什么样的课堂教学是有效的。学习金字塔可以帮助我们回答课堂教学有效性的问题 [5]。

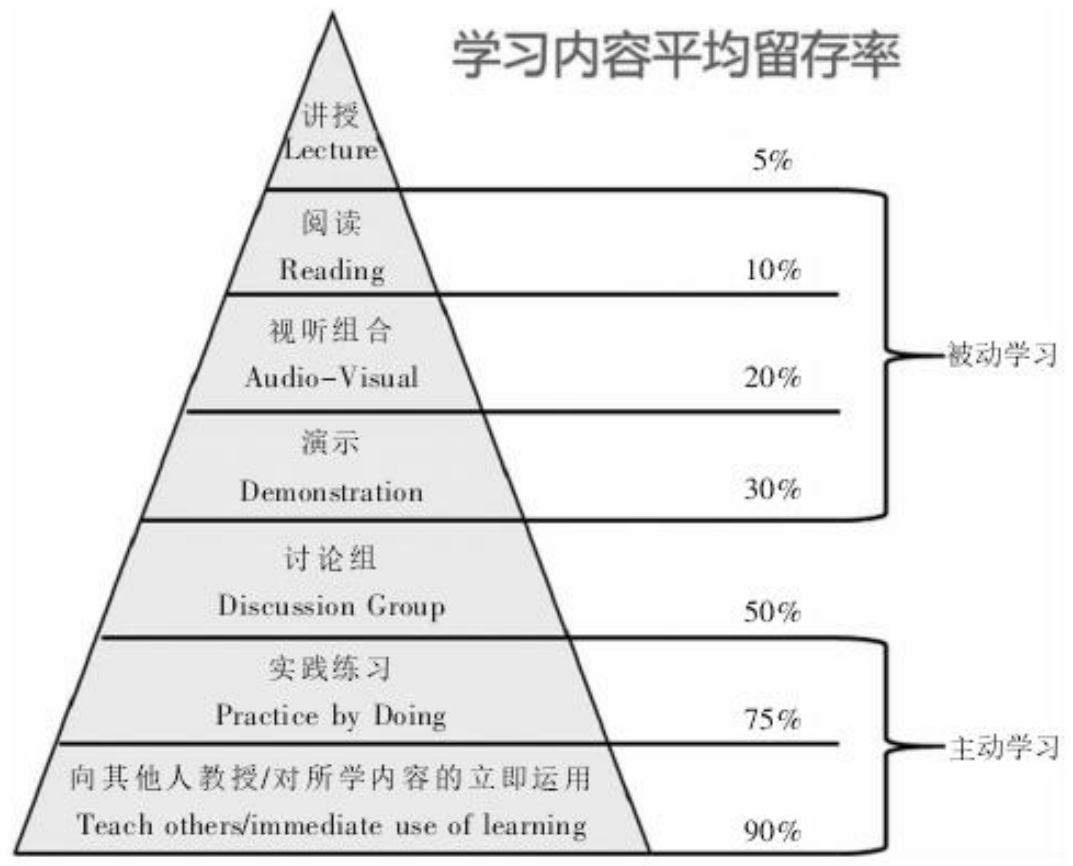

图 3 学习金字塔

学习金字理论从新的角度描述了提高学习效率的途径，揭示了从简单的照本宣科灌输式学习，到多 种感官参与的深入体验式学习给学习者带来的学习效率的改变。从图 3 反映出来各种方法在学习效率方面 的巨大差异，启示教师和学生都应做出调整甚至改变。

\section{3 课堂教学创新改革实践}

\section{1 人才培养方案的顶层设计}

从满足产业需求、满足学生发展的要求出发，立足技术技能型人才的培养，强化通识教育、规范实 践教学、引入优质教育资源、扩大学生选择权, 提出适合学生专业发展的弹性学分制人才培养方案改革实 施意见。建立集通识课、专业基础课、专业课和第二课堂重在素质养成与提升就业质量为导向的课程类别, 重点打造“公民素质+通用技能”的通识课程体系。 


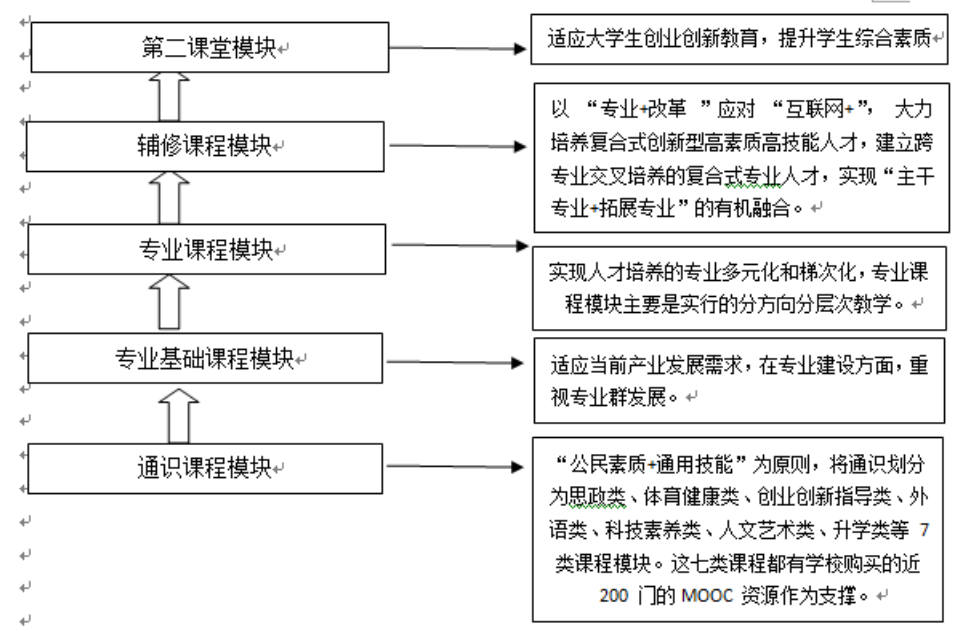

图 4 课程基本结构

\section{2 课堂教学创新的改革实践}

制定学校层面的课堂教学创新行动计划, 以课程为基础, 着力提高课程教学有效性, 培育和遴选一批 教学方法新颖、教学手段先进、教学特色鲜明、教学过程规范、教师教学艺术高超、受到广大学生欢迎的 示范课堂。

\subsection{1 五类优质课程建设。}

重点围绕教学团队建设、教学内容整合与优化、教学资源的体系化、完全教考分离和课堂教学改革, 培育和建设辐射面广的专业群内平台课程; 围绕规范实训教学组织, 推行学生操行评定, 提升实训课程 教学效果; 从课程内容、教学资源、教学方法、教学风采、互动活动等方面, 培育与建设示范微课, 并组 织校级微课竞赛; 购置网络学习平台, 以省、校级精品课程和工学结合课程为基础, 重点培育与转型校级 优质资源共享课, 实施 SPOC 教学; 重点探索行动导向教学、分层分类教学、小班化教学、翻转课堂、 课堂重建等教学方法创新。

\section{2.2 课堂教改项目建设。}

重视课堂教学改革项目, 重点围绕学分制及培养方案优化、校企利益共同体、教学评价改革、教学基 层组织建设、通识教育及教学创新、现代学徒制等领域, 设立专项招标课题。

\section{2 .3 推行混合教学模式改革。}

在混合教学中, 摒弃以往传统教学中以教师为中心的讲授式授课方式, 根据学习金字塔理论, 鼓励老 师采用更多的以启发、研讨、互动、交流为主的探究式教学方法 [6]。

(1) SPOC 翻转教学实践。SPOC 并不是大规模和完全对外开放的, 而是 Small 与 Massive 的（即 小规模和限制性), 它并不为所有人服务, 是一种具有很强针对性的课程模式 SPOC 是混合学习视角下对 MOOC 的一种创新, 它的在线学习的实现仍以 MOOC 平台为依托, 而 MOOC 平台上对学习过程的数据分 析和及时反馈等功能, 能够为师生创建更加优越的教学环境 [7]。学校针对公选课开课不足量的现状, 鼓 励公选课尤其是人文艺术类课程的老师, 以现有的国内外知名 MOOC 平台 (coursera、ewant、学堂在线、 中国大学 MOOC、MOOC 学院、华文慕课、好大学在线平台) 课程为资源, 实施 SPOC 教学。通常教师和 学生一起线上学习平台 $\mathrm{MOOC}$, 一起线上或线下研讨课程内容, 教师主要承担线下课程助教的角色。以《经 
典国学》公选课为例, 其学时和考核评价安排如图 5 所示:
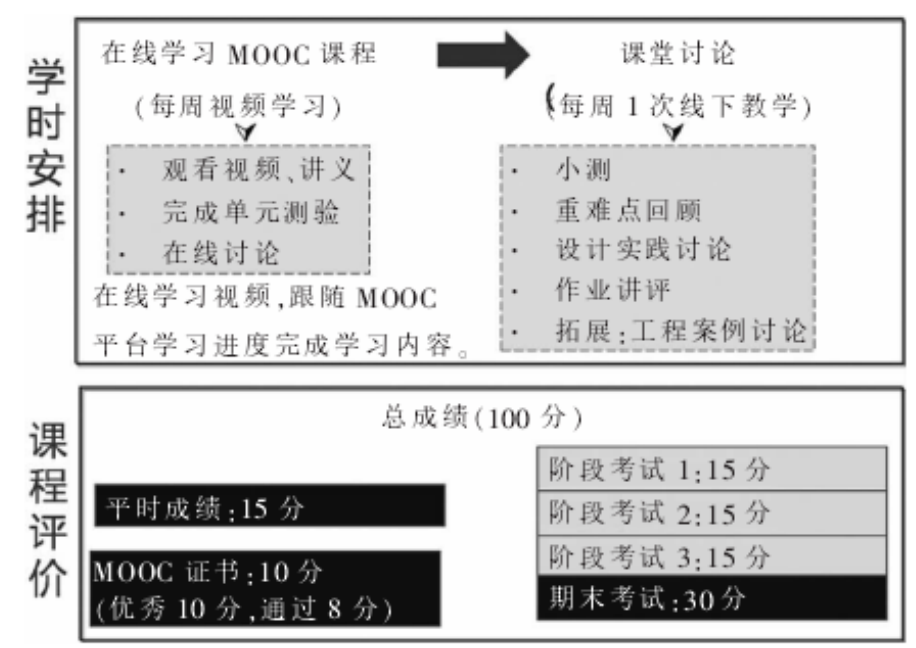

图 5 SPOC 教学安排——《经典国学》公选课为例

(2) 微课翻转教学实践。高职的学生大多不擅长抽象思维和演绎式为主的学习方式, 不习惯阅读长 篇文字, 不喜欢传统的课堂讲授教学方式 [8]。因此针对一些理论性较强的公共基础课和专业基础课程, 学 校通过翻转课堂教学改革项目立项, 试点先行一批青年教师利用各种网络教育资源结合自己的课程内容进 行课程资源建设, 开发并制作出课程的系列微课, 并开展翻转课堂教学。微课翻转课堂看似简单, 其实它 是一个较为复杂的教学系统, 有一整套完整的教学设计, 工作量是巨大。其实施过程大致分为可课前、 课中和课后三个环节 [9], 是一个师生不断互动与交流的过程, 具体流程如图 6 所示。

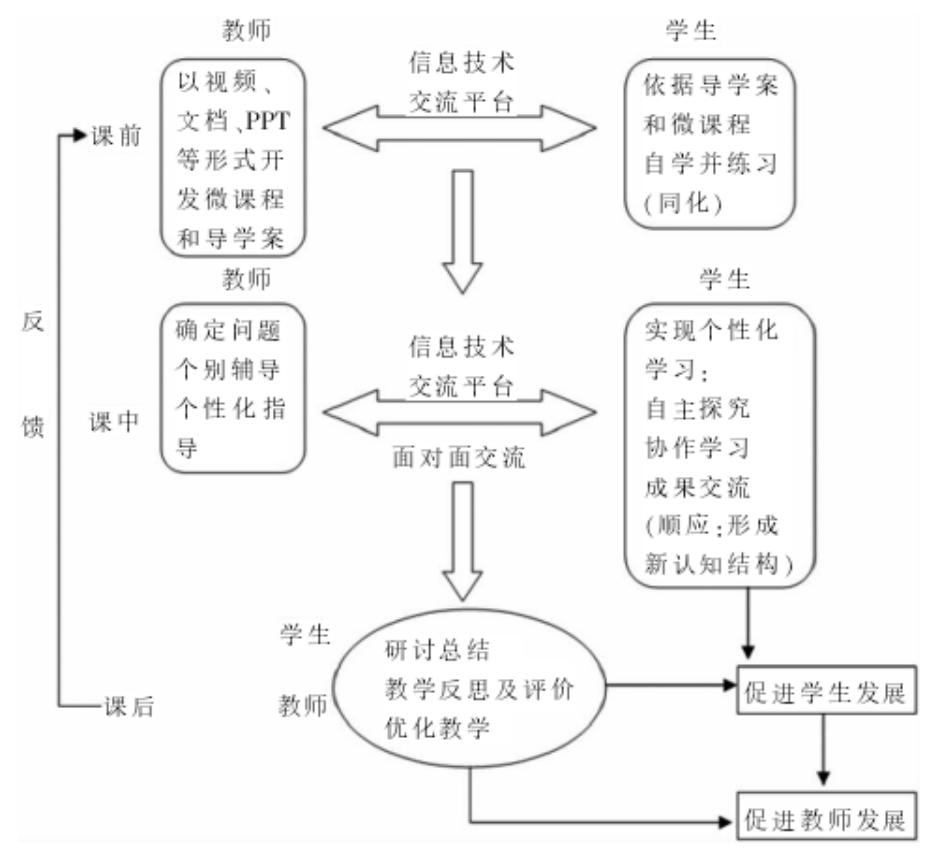

图 6 翻转课程教学过程

课中, 整个课堂将是以学生为中心的协作式探究学习方式, 教师主要负责对学生的个别化问题进行指 导和答疑。课后, 教师和学生都需要做一些总结工作, 检查学生对课程内容的掌握情况 [10]。 


\section{参考文献:}

[1] 中文互联网数据咨询中心 http://www. 199it. com/archives/264723. htm1

[2] 中文互联网数据咨询中心 http://www. 199it. com/archives/503417.html, 2016.

[3]基于 “互联网+” 视角的大学生创新创业教学 $[\mathrm{J}$ ． 张金山．中国高等教育．2016（9)：55-56

[4]现代职业教育体系建设规划（2014-2020 年）[EB/OL].

http://www. moe. edu. cn/publicfiles/business/htmlfiles/moe/moe_630/201406/170737.html, 2014.

[5]洪秦平. 资源整合赢天下 [M]. 北京: 中国经济出版社, 2011.

[6]何克抗. 我国教育信息化理论研究新进展 [J].中国电化教育, 2011（1）：1-19.

[7]郑德明. 资源整合赢天下 [M]. 北京：中华工商联合出版社，2014.

[8]中国教育技术网. 全国教育信息技术研究 “十二五” 规划 [EB/OL]. http://www. etr. com. cn, 2010.

[9]高校微课 “趋同进化” 教学设计促进翻转课堂教学策略研究 [J]. 郭绍青, 杨滨. 中国电化教育. 2014(04)

[10] 首鸿燕. 基于积件思想的网络教学资源库平台的构建与应用 [D]. 杭州: 浙江大学, 2005.

\section{References}

[1] Chinese Internet Data Center http://www.199it.com/archives/264723.html

[2] Chinese Internet Data Center http://www.199it.com/archives/503417.html,2016

[3] Innovation and Entrepreneurship Teaching of University Students Based on Perspective of the "Internet +" [J].Zhang Jinshan. China Higher Education.2016(9):55-56

[4] Construction Planning of Modern Vocational Education System (2014-2020) [EB/OL]. http://www.moe.edu.cn/publicfiles/business/htmlfiles/moe/moe_630/201406/170737.html, 2014.

[5] Hong Qinping. Resources Integration to Win the World [M].Beijing: Economic Press China, 2011.

[6] He Kekang. New Progress of Theoretical Research of Educational Informationization in China [J].China Educational Technology, 2011(1):1-19.

[7] Zheng Deming. Resources Integration to Win the World [M].Beijing: China Industrial \& Commercial United Press, 2011.

[8] China Education Technology Network. National Education Information Technology Research "Twelve-Five” Plan [EB/OL].http://www.etr.com.cn, 2010.

[9] Research on Teaching Design of University Micro-Class "Convergent Evolution" promotion of Teaching Strategy in Flip Classroom [J].Guo Shaoqing, Yang Bin. China Educational Technology.2014(04)

[10] Shou Hongyan. Construction and Application of Resources Platform in Network Teaching Based on Integrable Thought [D].Hangzhou: Zhejiang University, 2005. 